This item was submitted to Loughborough's Research Repository by the author.

Items in Figshare are protected by copyright, with all rights reserved, unless otherwise indicated.

\title{
Thermal analysis of orthogonal cutting of cortical bone using finite element
} simulations

PLEASE CITE THE PUBLISHED VERSION

http://dx.doi.org/10.1504/IJECB.2010.035259

PUBLISHER

(C) Inderscience Enterprises Ltd.

VERSION

AM (Accepted Manuscript)

LICENCE

CC BY-NC-ND 4.0

\section{REPOSITORY RECORD}

Alam, Khurshid, A.V. Mitrofanov, and Vadim V. Silberschmidt. 2019. "Thermal Analysis of Orthogonal Cutting of Cortical Bone Using Finite Element Simulations”. figshare. https://hdl.handle.net/2134/8237. 
This item was submitted to Loughborough's Institutional Repository (https://dspace.lboro.ac.uk/) by the author and is made available under the following Creative Commons Licence conditions.

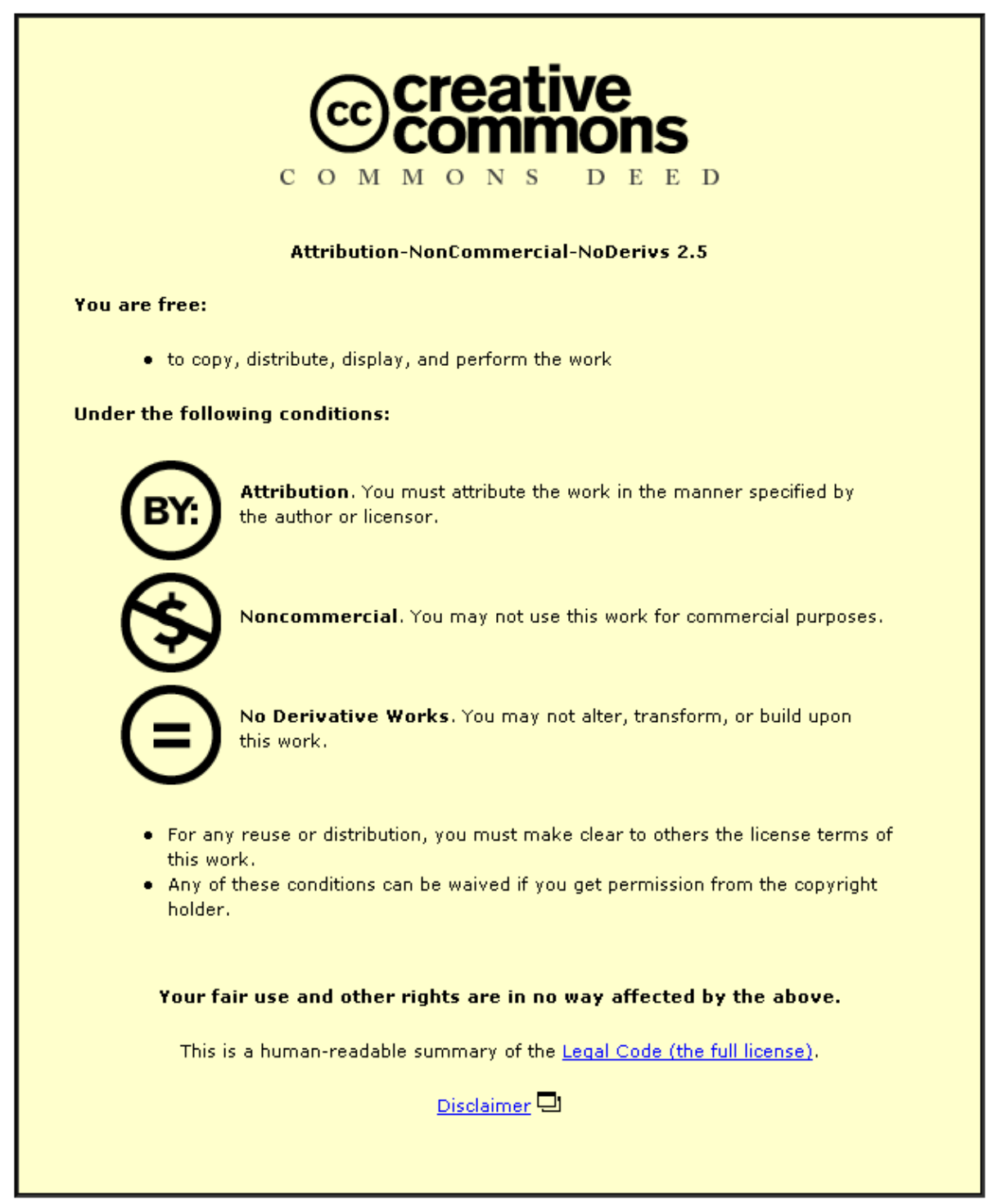

For the full text of this licence, please go to: http://creativecommons.org/licenses/by-nc-nd/2.5/ 


\title{
Thermal analysis of orthogonal cutting of cortical bone using finite element simulations
}

\author{
$\mathrm{K}$ Alam $^{1}$, A V Mitrofanov $^{1}$ and V V Silberschmidt ${ }^{1}$ \\ ${ }^{1}$ Wolfson School of Mechanical and Manufacturing Engineering, Loughborough University, \\ Loughborough, Leicestershire, LE11 3TU, UK \\ Corresponding author: Khurshid Alam \\ Institute: Wolfson School of Mechanical and Manufacturing Engineering \\ Engineering, Loughborough University \\ City: Leicestershire \\ Country: United Kingdom \\ Email: k.alam2@lboro.ac.uk \\ Phone: 00441509227534 \\ Fax: 00441509227648
}

Bibliographic notes: Khurshid Alam is a PhD student in the Wolfson School of Mechanical and Manufacturing Engineering, Loughborough University, United Kingdom. His research is mainly focused on the measurements of cutting force and temperatures in conventional and ultrasonically assisted bone cutting $\mathrm{He}$ has acquired his bachelor degree in Mechanical Engineering from University of Engineering and Technology Peshawar, Pakistan and his MSc in Design and Manufacturing from GIK Institute of Engineering Sciences and Technology Topi, Pakistan.

Dr Alex Mitrofanov: is a lecturer in Mechanics of Materials in the Wolfson School of Mechanical and Manufacturing Engineering, Loughborough University. Educated at St. Petersburg State Technical University, Russia, Alex has acquired his $\mathrm{PhD}$ in Mechanical Engineering from Loughborough University for his research into computational and experimental modelling of ultrasonically assisted cutting of high-strength aerospace alloys. He has also analysed the influence of ultrasonic vibration on the temperature and cutting force in bone drilling.

Prof. Vadim Silberschmidt is a Professor of Mechanics of Materials at the Wolfson School of Mechanical and Manufacturing Engineering, Loughborough University, UK. He heads the Mechanics of Advanced Materials Research Group and is also the Director of the International Centre of Vibro-Impact Systems. He is a Charted Engineer, an IMechE Fellow and a Fellow of the Institute of Physics, where he also chairs the Applied Mechanics Group. 


\title{
Thermal analysis of orthogonal cutting of cortical bone using finite element simulations
}

\begin{abstract}
Bone cutting is widely used in orthopaedic, dental and neuro surgeries and is a technically demanding surgical procedure. The major concern in current research is thermal damage of the bone tissue caused by high-speed power tools, which occurs when temperature rises above a certain tissue threshold value that is called bone necrosis. Hence optimization of cutting parameters is necessary to avoid thermal necrosis and improve current orthopaedic surgical procedures. In this study a thermo-mechanical finite element model of bone cutting is presented that idealizes cortical bone as an equivalent homogeneous isotropic material. Maximum temperature on the bone was found in the region where the thin bone layer (chip) was separated from the bone sample that was adjacent to the tool rake (i.e. front face of the tool) Temperature values were calculated and compared for cutting conditions with and without coolant (irrigation). The influence of bone thermal properties on the depth of thermal necrosis was discussed. The simulated cutting temperatures were compared with experimental results obtained from bone drilling tests. The cutting processes identified critical variables and cutting parameters that influence the thermo-mechanics of bone cutting.
\end{abstract}

Keywords: FE modelling; bone cutting; cutting temperatures; bone drilling; orthopaedic; irrigation; necrosis; bone properties; biomechanics; thermocouple

\section{Introduction}

Cutting of bones for orthopaedic and dental purposes has been a common practice for decades. It is a major part of bone surgery during preparation for insertion of a fixative orthopaedic implant such as a nail, screw or wire or before insertion of a bone graft to enhance bone healing. The number of patients suffering from osteoarthritis in an average population ranges from $12 \%$ to $20 \%$ of the total number and is expected to increase rapidly with the increasing aging trends in developed countries (Sugita et al., 2009). Temperature rise in bone cutting may cause tissue thermal damage (necrosis). Since thermal necrosis generally has a negative impact on the outcome of a cutting procedure, it is important to keep bone temperature below the threshold value above which the thermal necrosis is induced. Pallan (1960) has shown that necrosis breaks down the bone around the implantation site leading to the loosening of fixtures (screws, pins) and can dramatically weaken the whole structure. 
Hence data on temperature increase in the bone material during cutting is important for investigating and improving the current surgical procedures. However, studies describing the depth from the cut site at which bone tissue necrosis may occur are limited in the amount of information.

Researchers have developed several techniques to assess temperatures during highspeed cutting processes such as drilling. Some of these techniques are bone embedded thermocouples, tool embedded thermocouples and infrared photography. Drilling temperatures were measured in human and bovine cortical bone by placing a thermocouple inside a $3.2 \mathrm{~mm}$ diameter drill bit close to its cutting edge (Hillery and Shuaib, 1999). It was found that speeds of 800-1400 rpm provided the best cutting conditions and maintaining temperatures at a manageable level with feed rate up to $50 \mathrm{~mm} / \mathrm{min}$. The detailed description of measuring temperature in bone drilling using thermocouples inserted into the bone can be found in (Bachus et al., 2000; Krause et al., 1982; Abouzgia and James, 1997). Another study of temperature in drilling of bovine mandebular bone was conducted using Thermovision 900 system in (Benington et al., 1996). Thermal pictures were recorded surrounding the drilling areas without irrigation as infrared can not pass through water. The thermal camera was focused on the freshly milled surface behind the end mill.

Optimization of cutting parameters is necessary to evaluate thermally induced damage which will improve bone-implant/screw interfacial strength. Presently, this requires expensive experimental equipment and additional safety measures to protect from biohazards. Finite element modelling (FEM) of bone cutting could be an important extension to, and possible substitute for, experimental work as it eliminates equipment costs as well as potential health risks associated with biological materials. Modeling bone cutting using FEA may be useful for validation of experimental or analytical results and can be considered as a promising and reliable tool for the development of new surgical techniques within the near future. However, despite the capabilities of FEA in modeling various materials, it has only a few application in the area of biomechanics particularly in cutting of biomaterials. In fact, finite element studies describing thermo-mechanics of bone cutting have not been reported in the literature to date. Bone is of composite nature where osteons run parallel to the bone longitudinal axes in the interstitial bone. The material and structural complexity of bone is the main difficulty preventing bone cutting from being modelled with FEA.

In this paper, the influence of cutting parameters on the temperature rise in the bone material and the effect of cooling on cutting temperature were studied. The depth of thermal 
necrosis (DTN) was calculated as a distance from the cut surface where the thermal threshold level was reached. DTN was analysed and plotted as a function of cutting velocity, depth of cut (DOC) and bone thermal properties. The FE model was validated by temperatures measured in bone drilling experiments.

\section{Finite element model}

The MSC.Marc general FE code [Marc, 2007] was used in the development of a twodimensional FE model of bone cutting. A $2 \mathrm{~mm} \times 1 \mathrm{~mm}$ rectangular fragment of the bone was modelled. This fragment (called the workpiece below) was modelled with four-node, isoparametric, arbitrary quadrilateral elements and assuming plane-strain conditions. Frequent remeshing was applied to avoid convergence issues associated with highly distorted elements. The cutting tool was modelled with rigid lines as the stiffness of the tool material was much greater than that of the bone. A geometric representation of the FE model is shown in Figure 1.

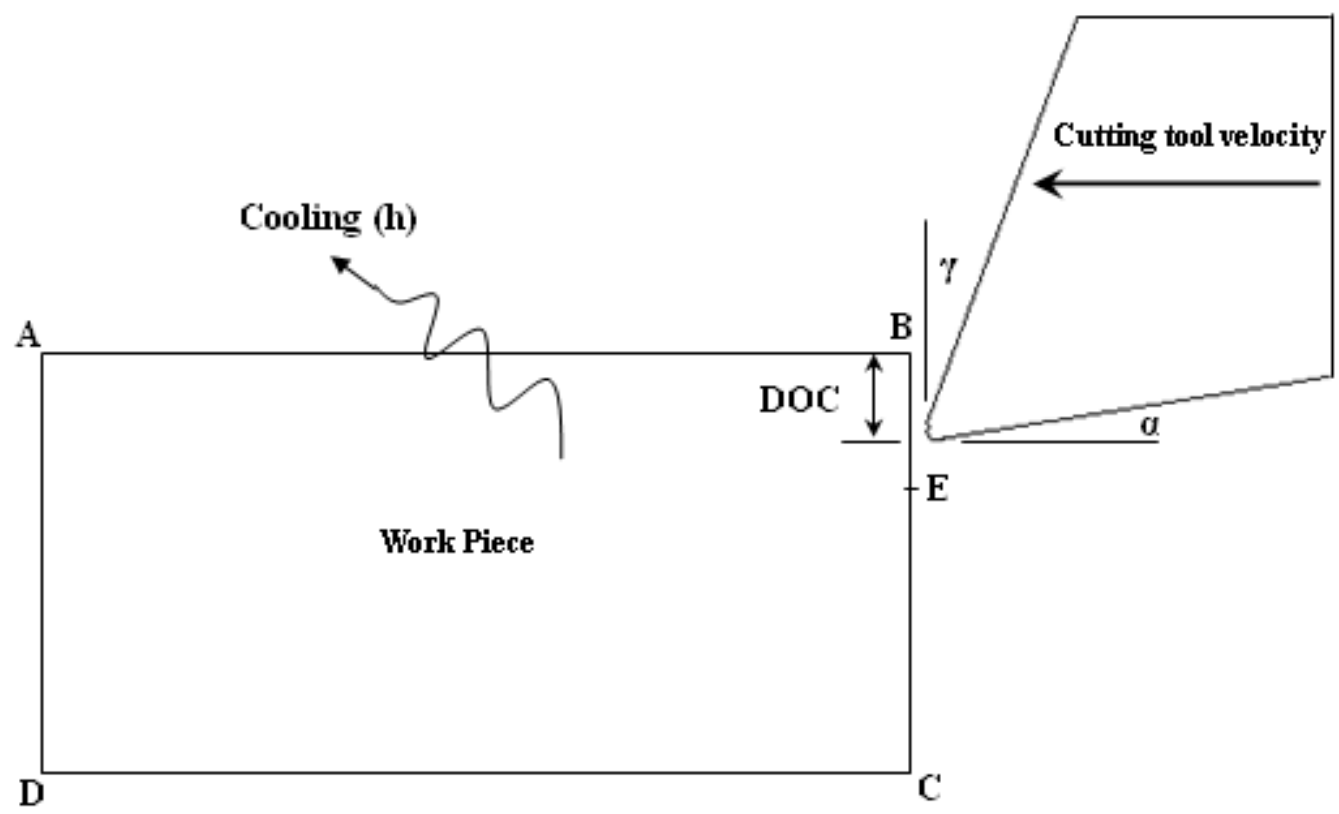

Figure 1 Geometric representation of the FE model for bone cutting.

The simulation interval was subdivided into 2,000 time increments of $1.25 \times 10^{-6} \mathrm{~s}$. Each simulation took about 5 hours of calculation time on Pentium IV, $2.8 \mathrm{GHz}$ workstation with 2048 MB RAM.

\subsection{Material data}


The bone tissue is a heterogeneous material with complex multi-level microstructure that was approximated in this paper with an equivalent homogeneous material (EHM). A middiaphysis of a fresh bovine femur (aged 3-4 years) was used in material data acquisition for the FE model. Bovine bone was used as according to Vasishth (2000), its mechanical, fracture and thermal properties are similar to those of a human bone.

In cortical bone, osteons (fibres) are imbedded into an interstitial bone (matrix). Nanonindentation tests were carried out on osteonal and interstitial bone to study the difference between their elastic moduli and their area ratios. A microscopic image $1 \mathrm{~mm} \times 1$ $\mathrm{mm}$ of bone cross section was taken and the ratio of the osteonal area to the interstitial bone was found. The rule of mixtures was used to calculate the effective elastic modulus of the equivalent homogeneous material. The calculated effective elastic constant (see Table 2) was incorporated into the FE model.

The Johnson-Cook (JC) material model that accounts for the strain rate sensitivity was utilised for the bone tissue in the current paper. The JC material model was previously successfully applied for modeling bone cutting (Alam et al., 2009; Alam et al., 2009) and is given by

$$
\sigma_{Y}=\left(A+B \varepsilon_{\mathrm{p}}^{n}\right)\left(1+C \ln \left(\frac{\dot{\varepsilon}_{p}}{\dot{\varepsilon}_{\mathrm{o}}}\right)\right)
$$

where $A, B, C$ and $n$ are constants and $\varepsilon_{p}$ and $\dot{\varepsilon}$ are the plastic strain and strain rate, respectively. Temperatures effects on bone properties were ignored at this stage of investigations due to the unavailability of reliable data.

In order to investigate the strain rate dependency of cortical bone, the following experiment has been conducted. Thirty dogbone-shaped specimens were extracted from the mid-diaphysis of bovine femur. The specimens were tested for three strain rates between $0.00001 \mathrm{~s}^{-1}$ to $1 \mathrm{~s}^{-1}$ with 10 samples for each strain rate. It was concluded that the yield stress was strain-rate dependent and that the rate effects at strain rates higher than $1 \mathrm{~s}^{-1}$ can be neglected. The JC constants were then calculated by fitting the equation into the stress-strain graphs for different load rates obtained from our experimental tensile tests on the bone. The JC parameters used in the simulations are given in Table 1 . The effective elastic modulus along with the published data on the bone properties used in the model are provided in Table 2. 
Table 1 Johnson-Cook parameters used in cutting simulations.

\begin{tabular}{llll}
\hline$A(\mathrm{MPa})$ & $B(\mathrm{MPa})$ & $C$ & $n$ \\
\hline 50 & 101 & 0.03 & 0.0 \\
\hline
\end{tabular}

Table 2 Material properties of cortical bone used in simulations

\begin{tabular}{lcc}
\hline \multicolumn{1}{c}{ Property } & Value & Reference \\
\hline Effective elastic modulus $(\mathrm{GPa})$ & 20 & calculated \\
Thermal conductivity $(\mathrm{W} / \mathrm{mK})$ & 0.56 & (Davidson and James, 2000) \\
Heat capacity $\left(\mathrm{J} / \mathrm{m}^{3} \mathrm{~K}\right)$ & $2.86 \times 10^{6}$ & (Huiskes, 1980) \\
\hline
\end{tabular}

\subsection{Process parameters}

Mechanical drills are the most common tools used in bone surgery. The drilling process has a very complex geometry, but it may be approximated as a $2 \mathrm{D}$ orthogonal cutting process at the outer corner of the cutting lip (Ozcelik and Bagci, 2006; Dolinsek, 2003). Although the cutting action in drilling and orthogonal cutting is different, the basic mechanism of chip removal is the same and thus the theory for orthogonal cutting is still applicable. The schematic of this approximation is shown in Figure 2.

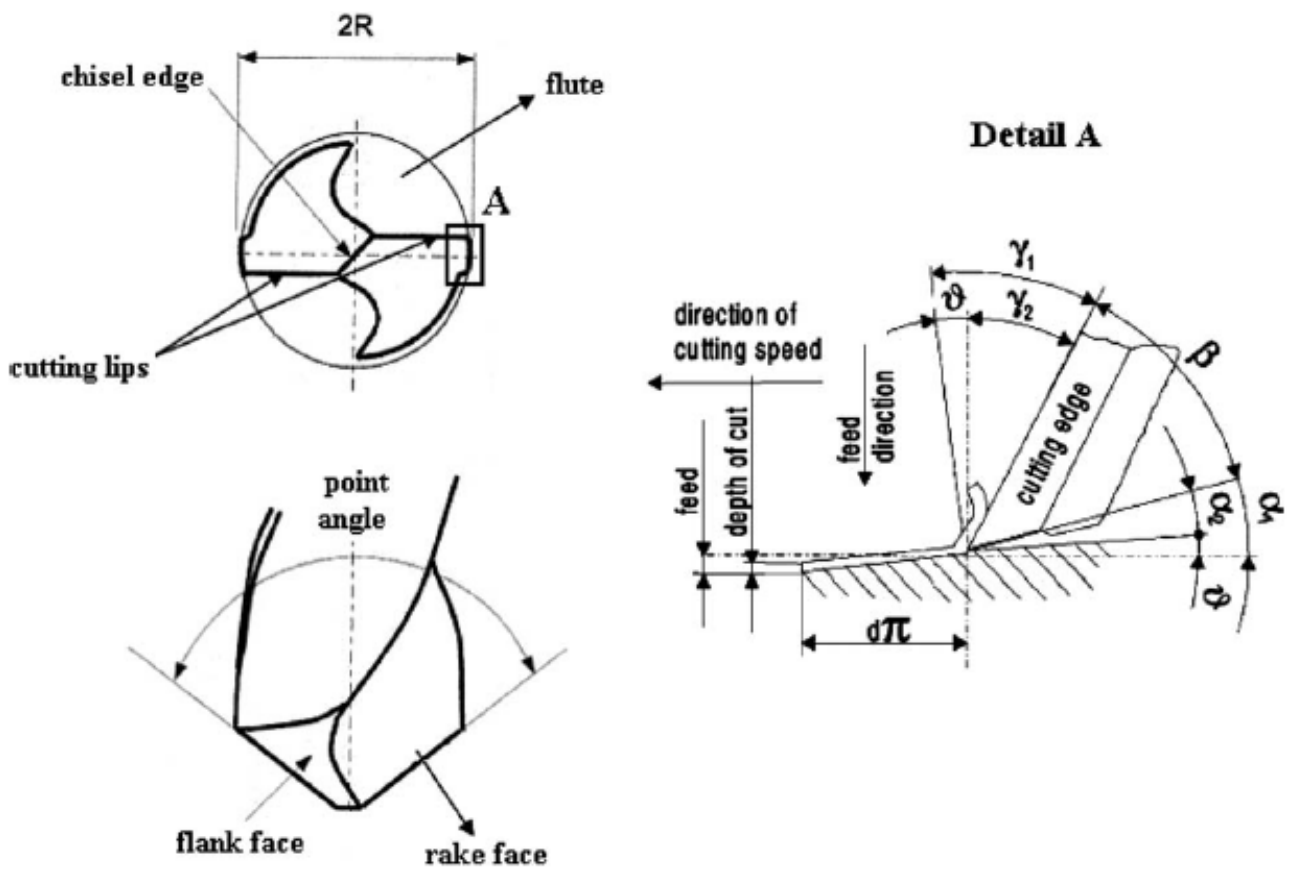

Figure 2 Cutting lips at the twist drill where the orthogonal cutting model can be applied

(Ozcelik and Bagci, 2006) 
The heat generation in cutting processes are strongly dependent on the physical and chemical properties of the material, cutting conditions and the cutting tool geometry. The regions where heat is generated during the orthogonal cutting process are shown in Figure 3. They are: (A) the primary deformation zone where plastic deformation takes place in the shear plane, (B) secondary deformation zone where additional deformation and sliding friction takes place at the tool/chip interface contact, and (C) tertiary deformation zone which is produced due to the rubbing contact between the tool flank face and the newly machined surface of the work piece.

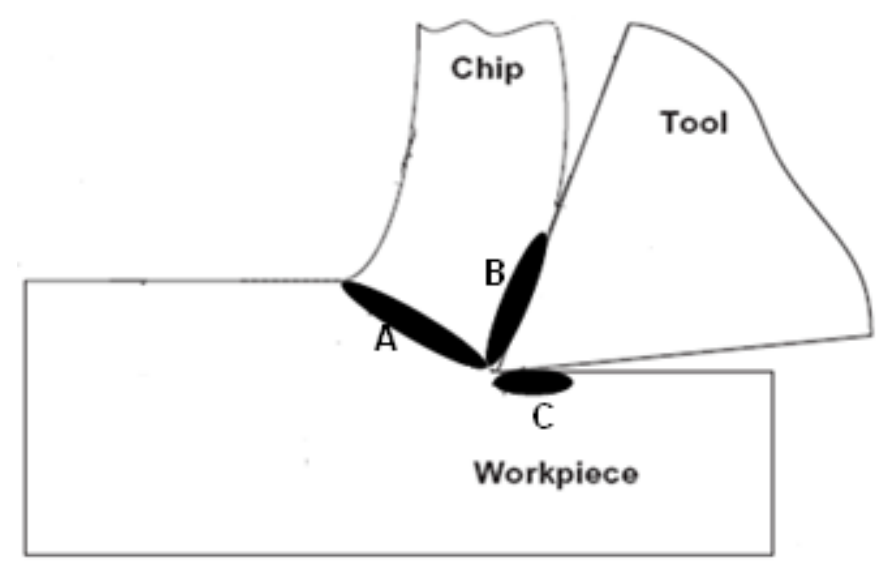

Figure 3 A scheme of the heat zones in orthogonal cutting: (A) primary deformation zone, (B) secondary deformation zone, and (C) tertiary deformation zone

The diameter of the drill used in orthopaedic bone drilling is generally 2-4 $\mathrm{mm}$ and its rotational speed is from $1000 \mathrm{rpm}$ to $3000 \mathrm{rpm}$. These parameters are widely reported in literature for drilling of bones (Hillery and Shuaib, 1999; Bachus et al., 2000). The range of tool cutting speeds $\left(V_{c}\right)$ considered in this paper was calculated as a conversion of the rotational speed at the outer corner of a $4 \mathrm{~mm}$ diameter drill into the linear one for the drill speed up to 3000 rpm using Equation 2.

$$
V_{c}=\frac{\pi \mathrm{DN}}{60} \ldots \ldots \ldots \ldots \ldots \ldots \ldots
$$

where $V_{c}$ is the linear cutting speed, $\mathrm{N}$ is the rotational speed in rpm and $\mathrm{D}$ is the diameter of the drill. As the exact frictional condition between the tool and bone was unknown, the value of friction coefficient (0.35) was taken from (Huang et al., 2003) due to the similarity in the chip formation behaviour between bone and wood. The value of the cutting edge angle and rake angle of an orthopaedic drill were measured and found to be $60^{\circ}$ and $20^{\circ}$, respectively, and were used in modeling of the cutting tool. The nose radius of the sharp edge of the tool 
was measured approximately as 10 micrometers based on a microscopic image. The maximum value of depth of cut (DOC) of $0.3 \mathrm{~mm}$ was chosen in simulations because above this value the generated chips in our bone plane cutting experiment were no longer continuous. The normal core body temperature of a healthy, adult human being is stated to be at $37^{\circ} \mathrm{C}$. Hence in all simulations, the initial temperature of work piece was assigned $37^{\circ} \mathrm{C}$ to mimic in vivo bone temperature. The cooling environment was modelled by applying a convective heat transfer coefficient (h) of the physiological saline solution commonly used in bone surgeries. In this study, convective heat transfer coefficient of a saline solution as measured in (Tangwongsan, 2003) for an average flow rate of $1000 \mathrm{ml} / \mathrm{min}$ was used in simulations. Cutting parameters used in simulations are provided in Table 3.

Table 3. Cutting parameters used in simulations of the bone cutting process.

\begin{tabular}{lc}
\hline \multicolumn{1}{c}{ Parameters } & \multicolumn{2}{c}{ Magnitude used in FEA } \\
\hline Cutting speed, $V_{c}(\mathrm{~mm} / \mathrm{s})$ & $100 ; 200 ; 300 ; 400 ; 500 ; 600$ \\
Friction coefficient & 0.35 \\
Tool nose radius $(\mu \mathrm{m})$ & 10 \\
Tool rake angle, $\gamma(\mathrm{deg})$ & 20 \\
DOC $(\mathrm{mm})$ & $0.1 ; 0.15 ; 0.2 ; 0.25 ; 0.3$ \\
Bone initial temperature $\left({ }^{\circ} \mathrm{C}\right)$ & 37 \\
Convection heat transfer, $\mathrm{h}\left(\mathrm{W} / \mathrm{m}^{2} \mathrm{~K}\right)$ & $0 ; 8000$ \\
\hline
\end{tabular}

\section{Analysis of cutting temperatures}

To study the effect of different processing parameters on cutting temperatures, a series of simulations were conducted. Fully thermo-mechanically coupled FE model was produced that allowed the study of temperature rise in the bone material. Simulation parameters, such as cutting velocity, DOC and cooling conditions were changed to observe their effect on temperature rise. Low level fluctuations were found in temperature values in chip due to remeshing and were smoothed in the results. The FE model presupposed formation of the continuous chip, which is in a good agreement with the results of our high-speed filming experiments of bone drilling and other results reported (Naohiko et al., 2006; Mitsuishi et al., 2004). After reaching the saturated level when the chip was fully generated (when the toolchip contact length reached a constant value), the temperature stayed constant for the remaining length of cut. The temperature rise was due to the rate of deformation as well as to the friction 


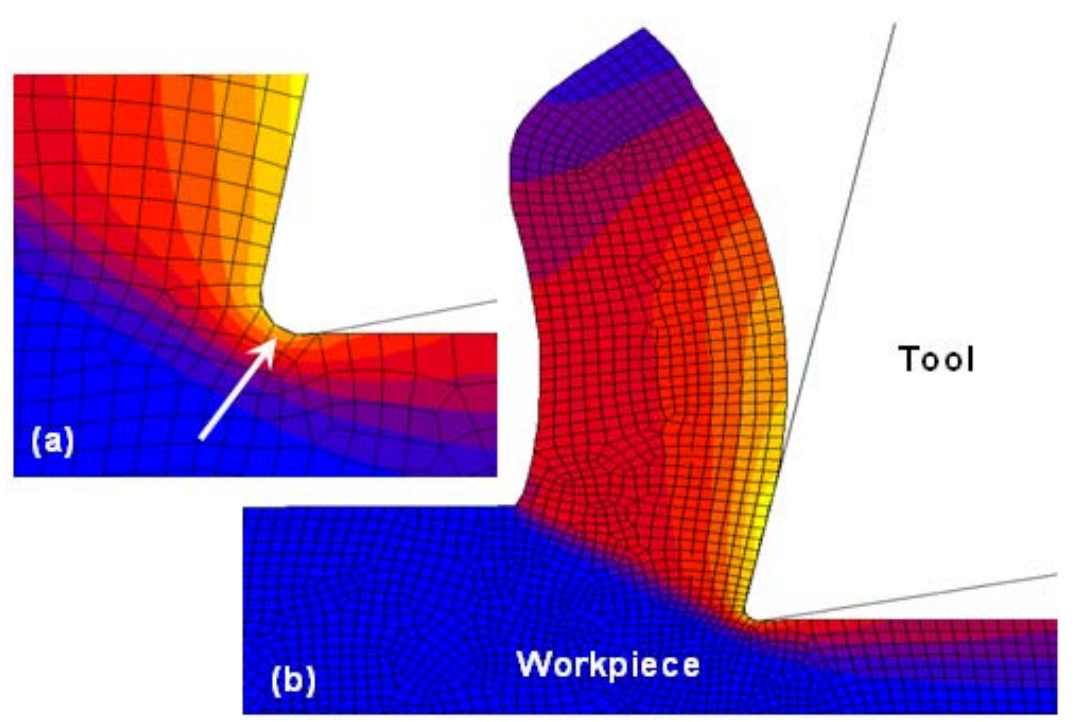

Figure 4 Temperature distribution in the cutting region. (a) a close-up view of the cutting edge - the arrow indicates the temperature produced below the freshly cut surface. (b) workpiece-tool interaction. $V_{c}-400 \mathrm{~mm} / \mathrm{s}$, DOC - $0.2 \mathrm{~mm}$.

between the tool and the workpiece material. The calculated temperature distributions at various regions for the condition when the chip was fully developed are shown in Figure 4. The heat was produced in three regions (see Figure 3). The highest proportion of heat was produced in the chip (in primary and secondary deformation zones); however the chip was considered to be no more part of the bone and its temperature was ignored. Instead, the temperature produced in the workpiece material near the flank of the tool (see a zone indicated by an arrow in Figure 4) was considered for the analysis.

\subsection{Investigation of Necrosis Threshold Level (NTL)}

The average temperature at which the necrosis most likely appeared was reported at a threshold around $50-70^{\circ} \mathrm{C}$ (Moritz and Henriques, 1947; Lundskog, 1972; Eriksson and Albrektsson, 1983; Frolke et al., 20001). In this study, a threshold level for thermal necrosis was taken as $70^{\circ} \mathrm{C}$ as reported in (Moritz and Henriques, 1947). The value on the ordinate, $\Delta \mathrm{T}$ of the subsequent plots in Section 3, represents the rise in temperature in bone material above $37^{\circ} \mathrm{C}$.

\subsection{Temperatures vs. tool speed}

The effect of cutting speed on the temperature rise in the bone material was investigated. The tool penetrated into the material and the chip started separating and sliding along the tool rake. Higher velocities developed the chip quickly and hence the temperature increased faster too. The effect of tool velocity on the temperature calculated in the workpiece material 
adjacent to the tip of the tool and with no cooling environment is shown in Figure 5. A temperature rise with increase in cutting velocity was due to the increase in the rate of deformation. For the material properties used in the model, the thermal necrosis threshold level was registered at the cutting speeds of $400 \mathrm{~mm} / \mathrm{s}$ and $600 \mathrm{~mm} / \mathrm{s}$.

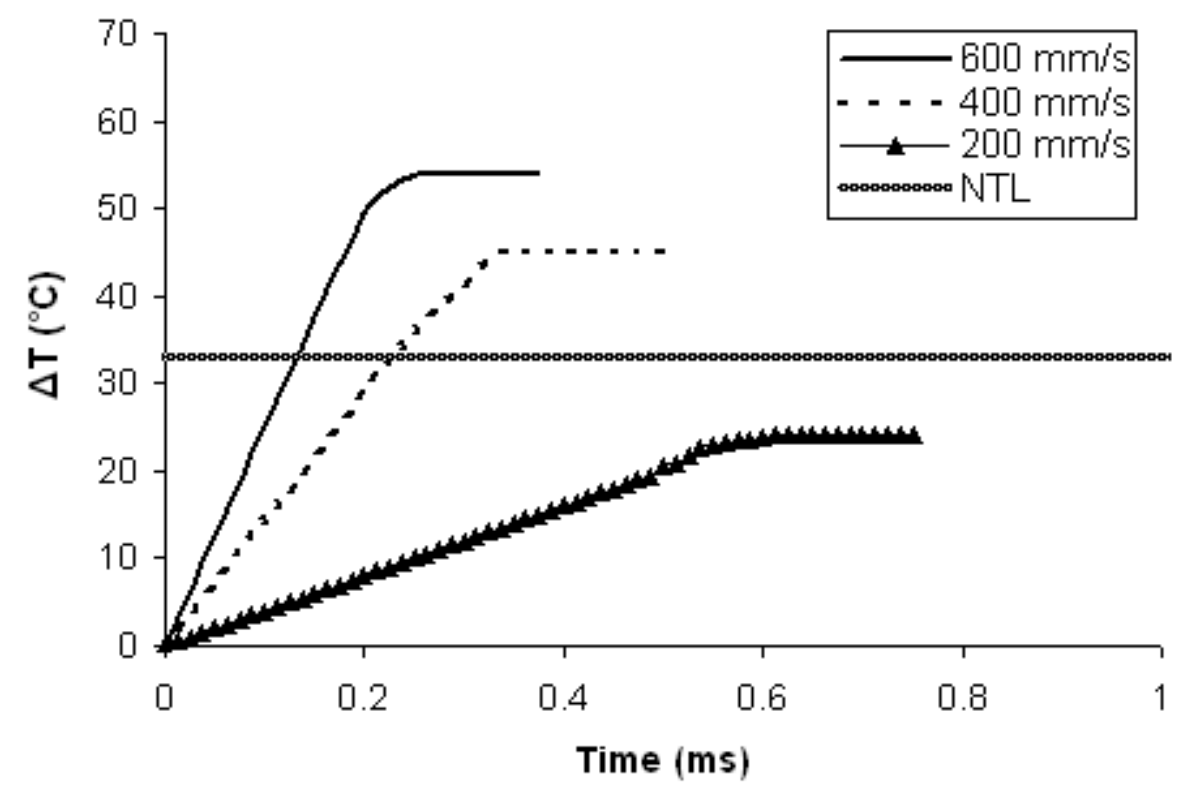

Figure 5 Effect of cutting speed on temperature evolution in bone, DOC $=0.2 \mathrm{~mm}, \mathrm{~h}=0$, bone initial temperature is $37^{\circ} \mathrm{C}$ (NTL - necrosis threshold level)

\subsection{Effect of cooling (irrigation)}

In orthopaedic bone cutting, the bone is irrigated by a saline solution as a coolant to maintain the temperature at a controlled level. The effect of cooling on the maximum temperature in bone was studied and, not surprisingly, a significant decrease in temperature was achieved when the irrigation environment was employed as shown in Figure 6. Without cooling, thermal necrosis was found for the range of cutting speeds 


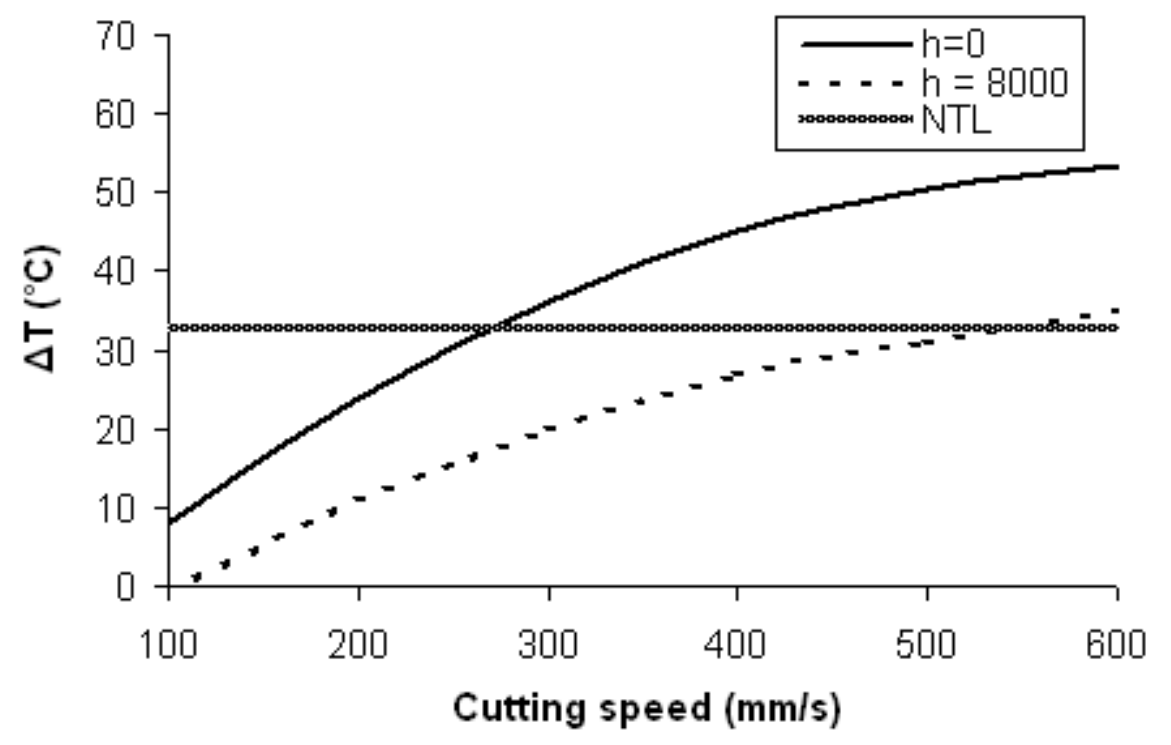

Figure 6 Effect of cutting speed on temperature with $\left(\mathrm{h}=8000 \mathrm{~W} / \mathrm{m}^{2} \mathrm{~K}\right)$ and without cooling $(\mathrm{h}=0)$, DOC - $0.2 \mathrm{~mm}$ (NTL-Necrosis threshold level)

above $300 \mathrm{~mm} / \mathrm{s}$. In comparison, a calculated rise in temperature did not reach the necrotic level for the cutting speeds below $550 \mathrm{~mm} / \mathrm{s}$ when the cooling condition was applied. A similar influence of cutting speed on material temperatures in bone was briefly discussed in (Hillery and Shuaib,1999).

\subsection{Effect of Depth of Cut (DOC)}

To investigate the effect of DOC on bone temperature, simulations were run using a constant cutting speed, $400 \mathrm{~mm} / \mathrm{s}$. The cutting speed was arbitrarily choosen and was not changed to calculate the effect caused by DOC only. It is evident from the results in Figure 7 that the temperature increased parabolically with increasing DOC. The slope of the curve, slowly decreased with increasing DOC. This can be related to the increase in frictional effects (increase in chip-tool contact length along the rake face) for higher DOC. For the material properties used in simulations, thermal threshold level (NTL) was calculated when the DOC was above $0.125 \mathrm{~mm}$ for the condition when no cooling was applied. Increasing DOC above $0.2 \mathrm{~mm}$ did not result in a significant temperature growth which was due to the fact that the temperature increased more in the secondary deformation zone (labelled B in Figure 3) due to the increased contact length between the tool and workpiece. 


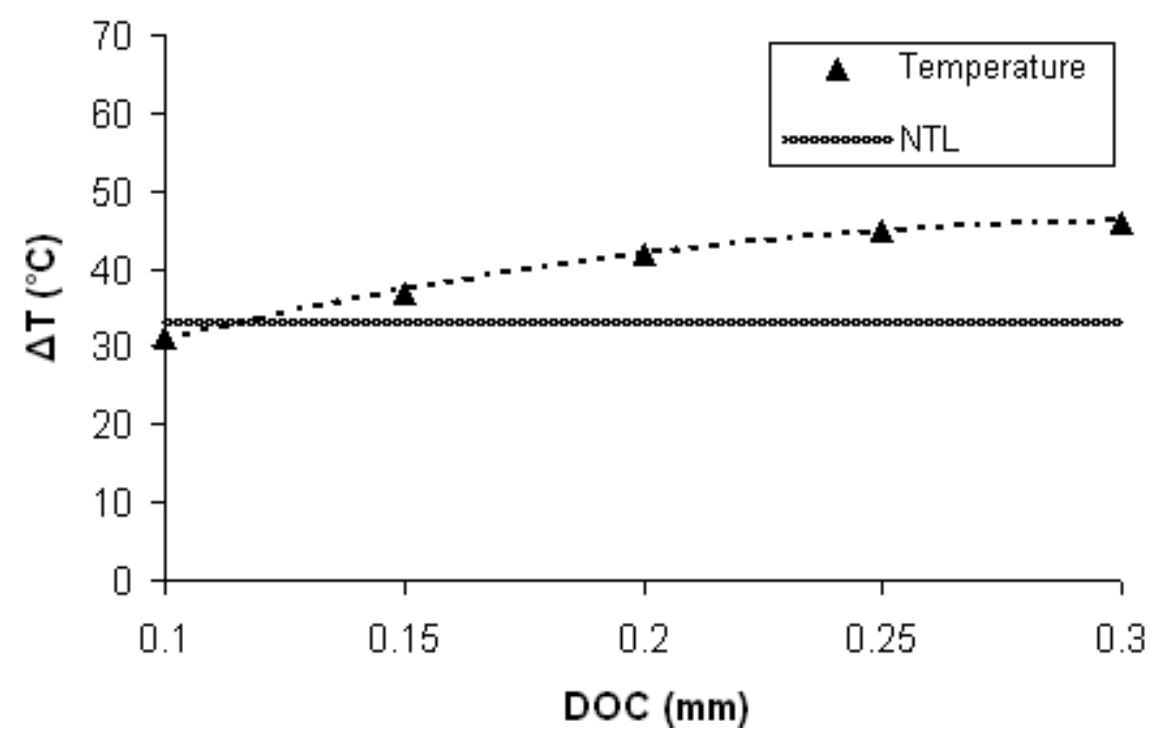

Figure 7 Effect of DOC on cutting temperature, $V_{c}-400 \mathrm{~mm} / \mathrm{s}, \mathrm{h}=0$

\subsection{Investigating depth of thermal necrosis (DTN)}

Maximum temperature in the bone material was found in the chip region adjacent to the tool rake and near the flank of the tool. Heat generated beneath the cutting edge caused the temperature to rise below the freshly cut surface near the tool flank (see figure 4). The term DTN was referred to the depth in micrometers below the cut surface where necrosis level was reached. The ordinate values in Figure 8 represent the depth from the cut surface where the threshold level $\left(70^{\circ} \mathrm{C}\right)$ was calculated. The necrotic levels were taken when the chip was fully developed and temperature values had stabilised. The threshold level was observed to depend strongly on the tool velocity and DOC. The threshold depth was observed to increase with an increase in DOC. This was due to the fact that growing DOC amplified the frictional effect due to larger contact between the tool and workpiece resulting in a higher temperature rise in the bone material. The DTN was negligible up to the cutting speed of $200 \mathrm{~mm} / \mathrm{s}$ for all values of DOC. 


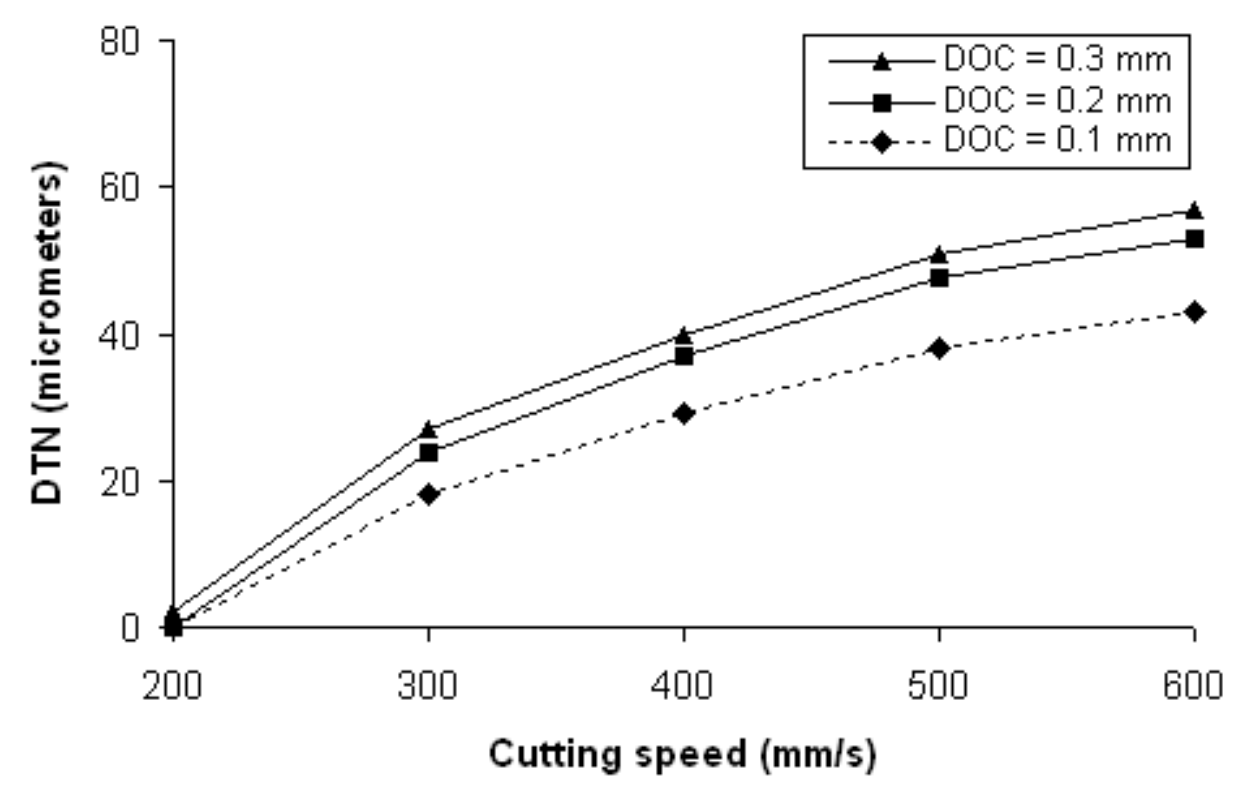

Figure 8 Effect of cutting velocity and DOC on the depth of thermal necrosis, h=0

\subsection{Effect of bone thermal properties on DTN}

Thermal properties of the bone material which influence cutting temperatures include the thermal conductivity and heat capacity. A temperature rise in the machined material generally decreases as these parameters increase. Bone thermal conductivity and heat capacity vary significantly among individuals and it is important to investigate their effect on DTN. Simulations were performed in which the thermal conductivity and heat capacity were each varied from $-20 \%$ to $+20 \%$ of their nominal values given in Table 2 . The ranges of thermal conductivity $(0.45-0.67 \mathrm{~W} / \mathrm{mK})$ and heat capacity $\left(2.29 \times 10^{6}-3.43 \times 10^{6} \mathrm{~J} / \mathrm{m}^{3} \mathrm{~K}\right)$ were used in simulations. According to the simulation results in Figure 9, thermal conductivity had a negligible effect on DTN, while a $20 \%$ increase in heat capacity resulted in a $46 \%$ decrease in necrosis penetration. A similar effect of the described properties on the necrosis propagation in bone drilling was reported in [Davidson, 2003]. 


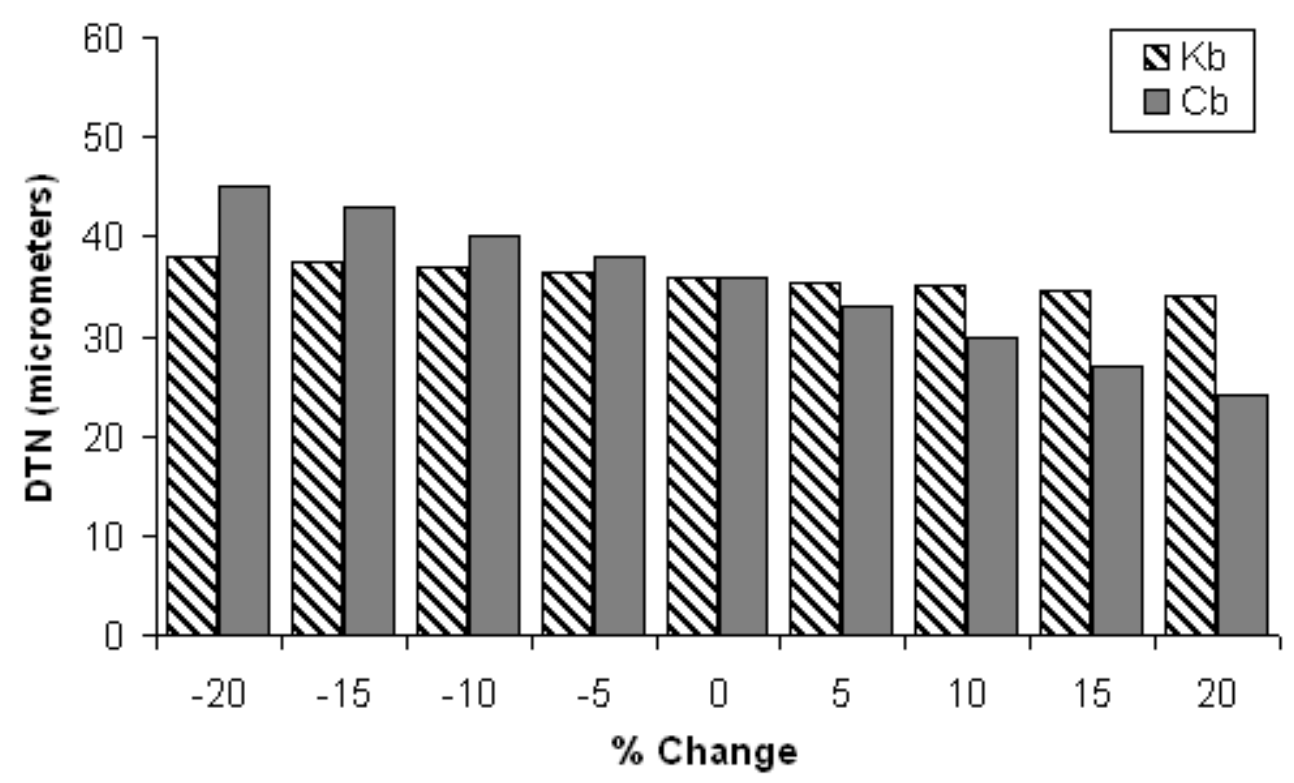

Figure 9 Influence of \% change in bone thermal conductivity $\left(\mathrm{K}_{\mathrm{b}}\right)$ and heat capacity $\left(\mathrm{C}_{\mathrm{b}}\right)$ on depth of thermal necrosis. $V_{c}-400 \mathrm{~mm} / \mathrm{s}$, DOC - $0.2 \mathrm{~mm}$.

\section{Experimental verification of the FE model}

To validate the developed model of bone cutting, experimental measurements of drilling temperatures for a real bone tissue were conducted. FE results were compared to temperature values obtained from drilling experiments. Results of a 2D FE model may be compared to a cutting process such as turning of bone where a single point cutting tool is utilized, but the shape of bone restricts such operation. Hence, the FE model was validated by drilling experiment using a bone-imbedded thermocouple. For temperature measurements, five tests were performed for each drilling speed. A hole of $1 \mathrm{~mm}$ diameter was drilled for inserting thermocouple in the direction parallel to the bone axis. The thermocouple was placed at a distance of $1 \mathrm{~mm}$ from the drilling tract. This was done to avoid the thermocouple being crushed by the drill. The initial temperature of bone was measured as $25^{\circ} \mathrm{C}$. All experiments were performed without irrigation (cooling) at the drill site. Tests were conducted only in the direction perpendicular to the bone axis (i.e. normal to the osteonal direction). To compare the simulated/calculated and measured temperature growth in the bone tissue, analyses were run by assigning the initial temperature of $25^{\circ} \mathrm{C}$ to the workpiece with no cooling condition applied.

\subsection{Specimen preparation for drilling}

Drilling tests were carried out on a bovine femur. The bone used in drilling experiments was taken from the same animal and anatomical location as that investigated in the material data 
acquisition tests. The bone was obtained from a local butcher where it had been boned (meat removed) and was stored frozen at $-10^{\circ} \mathrm{C}$ before the experiment. The maximum period of storage prior to experiment was one week. Periosteum was removed from the outer surface of the bone specimen as it caused the drill flutes to clog. The middle-diapysis was cut from the femur having an average thickness of the cortical wall of $10 \mathrm{~mm}$.

\subsection{Experimental equipment}

Drilling tests were performed using a vertical drilling machine. Standard $\mathrm{K}$ type insulated thermocouples with the wire diameter of $127 \mu \mathrm{m}$ were used for temperature measurements. At the beginning of each set of test, the calibration of the thermocouples was verified against a laboratory thermometer within $\pm 0.3{ }^{\circ} \mathrm{C}$. The K-type thermocouple can take measurement values up to $500^{\circ} \mathrm{C}$ with a response time of $10 \mu \mathrm{s}$. For temperature acquisition, FMSDL48 data logger (Glasgow, UK) was used. An instrument calibration was performed before the experiments against the mercury thermometer. The system error of approximately $\pm 1^{\circ} \mathrm{C}$ was found for temperature measurements. An experimental setup for drilling with bone-imbedded thermocouple is shown in Figure 10.

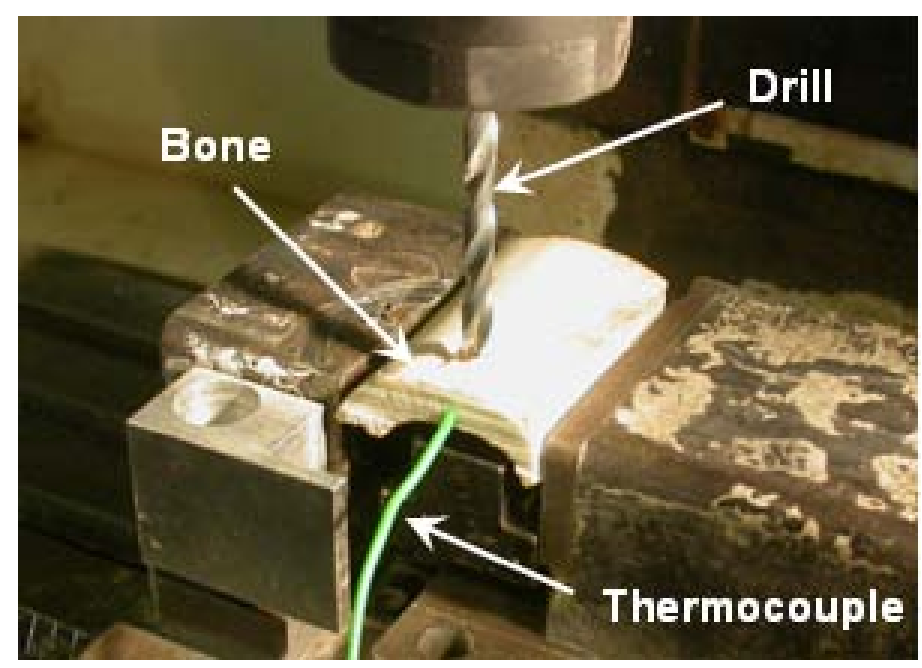

Figure 10 An experimental arrangement for temperature measurements using a boneimbedded thermocouple

\subsection{A comparison of experimental and finite element results}

The rotational speed of the drill at the outer corner was converted into linear one using Equation 1 and the latter was used in simulations (see Table 4). For comparison of the experimental and calculated results, the bone initial temperature was measured as $25^{\circ} \mathrm{C}$ and was used in simulations. Here, $\Delta \mathrm{T}$ represents the rise in temperature in the bone material 
above $25^{\circ} \mathrm{C}$. The temperature was measured as a function of cutting speed for different drilling speeds and compared with the results obtained from the 2D FE orthogonal cutting model. The maximum temperature showed an increase with the cutting speed which is consistent with the experimental findings. The difference between the experimental and calculated temperature values, for drilling speed of $3000 \mathrm{rpm}$ was about $21 \%$. The discrepancies between the measured and calculated and simulated temperatures may be attributed to simplification/assumptions in the FE model such as material homogenisation and the reported thermal properties of cortical bone tissue used in simulations. Another obvious reason for the difference was that the measurements were obtained from the thermocouple that placed at a $1 \mathrm{~mm}$ distance from the cutting edge of the drill in the experiments. The difference between the measured and calculated temperatures at higher cutting speeds could be due to the increase in the frictional resistance at the increased drilling speed. However, given all of the inherent complexities in predicting and measuring drill temperatures over a range cutting speeds, the predictive model is reasonably accurate.

Table 4 Comparison of the temperature rise on the bone as obtained from experimental drilling tests and FE calculations. Experimental results are the mean value for five drilling tests. $\mathrm{D}=4 \mathrm{~mm}, \mathrm{~h}=0$

\begin{tabular}{|c|c|c|c|c|}
\hline \multirow{3}{*}{ Drilling speed, N (rpm) } & \multirow{3}{*}{$\begin{array}{c}V_{c}=\frac{\pi \mathrm{DN}}{60} \\
(\mathbf{m m} / \mathbf{s})\end{array}$} & \multicolumn{3}{|c|}{$\Delta \mathrm{T}\left({ }^{\circ} \mathrm{C}\right)$} \\
\hline & & \multicolumn{2}{|c|}{ Experimental } & \multirow{2}{*}{ FEA } \\
\hline & & Mean (SD) & [Range] & \\
\hline 600 & 126 & $5(1.87)$ & [3-7] & 11 \\
\hline 1000 & 209 & $20.2(3.1)$ & [17-25] & 26 \\
\hline 1400 & 293 & $38.6(2.79)$ & [36-42] & 34 \\
\hline 1800 & 377 & $50.8(3.35)$ & [47-55] & 42 \\
\hline 2200 & 461 & $57.8(3.56)$ & [52-61] & 48 \\
\hline 2600 & 544 & $67.2(4.87)$ & [60-72] & 52 \\
\hline 3000 & 628 & $69.2(3.96)$ & [64-73] & 54 \\
\hline
\end{tabular}

\section{Conclusions}

Research into the bone cutting temperature is crucial, in addition to a study of the accuracy of the shape of the cut which may affect the strength between the bone and fastening components and the level of cutting force to allow smooth penetration. A thermomechanically coupled two-dimensional finite-element model of bone cutting was developed to simulate temperatures during the high-speed cutting process. The model allowed the study of chip formation and predictions of temperature rise in the bone material. The model is fully parametric and can simulate the cutting process for various cutting parameters, such as cutting 
speed, tool geometry and cooling conditions. Higher cutting speeds were observed critical in inducing thermal necrosis of bone tissue. A saturation in temperature was not observed for the range of cutting speeds studied in the paper and may be confirmed by complementary experimental tests. By inducing a coolant conditions in simulations, it was possible to increase the allowable level of cutting speeds that did not induce temperatures over the necrosis threshold by $67 \%$. In the presence of adequate cooling conditions, cutting speeds up to $550 \mathrm{~mm} / \mathrm{s}$ may be used without the risk of inflicting thermal injury to the bone tissue. This cutting speed correspond to a drilling speed of approximately $2600 \mathrm{rpm}$ for a drill of $4 \mathrm{~mm}$ diameter. The temperature rise and necrosis penetration were noted to have been affected by cutting speed, DOC and bone thermal properties. Appropriate control of such factors will allow to prevent the thermal necrosis and hence enable bone regeneration and its stronger attachment to the implants. Currently our finite element model rely on the bone thermal properties reported in the literature and need to be obtained experimentally for the same bone used in the experiments in future. To sum up various findings, it is evident that the subject of bone necrosis is a complex one, and the debate continues on how the results of such studies should be reflected in clinical practice.

\section{References}

Abouzgia, M.B. and James, D.F. (1997) 'Temperature rise during drilling through bone', International Journal of Oral and Maxillofacial Implants, Vol. 12, pp.342-353.

Alam, K., Mitrofanov, A.V. and Silberschmidt, V.V. (2009) 'Finite element analysis of forces of plane cutting of cortical bone', accepted for publication in Computational Materials Science.

Alam, K., Mitrofanov, A.V., Bäker, M. and Silberschmidt, V.V. (2009) 'Stresses in ultrasonically assisted bone cutting', accepted for publication in Journal of Physics: Conference Series.

Benington, I.C., Biagioni, P.A., Crossey, P.J., Hussey, D.L., Sheridan, S. and Lamey, P.J. (1996) 'Temperature changes in bovine mandibular bone during implant site preparation: an assessment using infra-red thermography', Journal of Dentistry, Vol. 24, pp.263-267.

Bachus, K.N., Rondina, M.T. and Hutchinson, D.T. (2000) 'The effects of drilling force on cortical temperatures and their duration: an in vitro study', Medical Engineering \& Physics, Vol. 22, pp.685-691. 
Bachus, K.N., Rondina, M.T. and Hutchinson, D.T. (2000) 'The effects of drilling force on cortical temperatures and their duration: an in vitro study', Medical Engineering and Physics, Vol. 22, pp.685-691.

Davidson, S.R.H. and James, D.F. (2000) 'Measurement of thermal conductivity of bovine cortical bone', Medical Engineering and Physics, Vol. 22, pp.741-747.

Davidson, S.R.H. and James, D.F. (2003) 'Drilling in Bone: modeling heat generation and temperature distribution’, Journal of biomechanics, Vol. 125, pp.305-314.

Dolinsek, S. (2003) 'Work-hardening in the drilling of austenitic stainless steels', Journal of Material Processing Technology, Vol.133, pp.63-70.

Eriksson, A.R. and Albrektsson, T. (1983) 'Temperature threshold levels for heat-induced bone tissue injury: a vital-microscopic study in the rabbit', Journal of Prosthetic Dentistry, Vol. 50, pp.101-107.

Frolke, J.P.M., Peters, R., Boshuizen, K., Patka, P.F., Bakker, C. and Haarman, H.J.T.M. (2001) 'The assessment of cortical heat during intramedullary reaming of long bones', Injury, Vol. 32, pp.683-688.

Hillery, M.T. and Shuaib, I. (1999) 'Temperature effects in the drilling of human and bovine bone’, Journal of Materials Processing Technology, Vol. 92-93, pp.302-308.

Huang, H., Chen, S. and Tang, J. (2003) 'Analyses of rotating disc cutting of wood', Taiwan Journal of Forest Science, Vol. 18, pp.263-271.

Huiskes, J. (1980) 'Some fundamental aspects of human joint replacement', Acta Orthopaedica Scandinavica, Supplementum, Vol. 185, pp.44-108.

Krause, W.R., Bradbury, D.W., Kelly, J.E. and Lunceford, E.M. (1982) 'Temperature elevations in orthopaedic cutting operations', Journal of Biomechanics, Vol. 15, pp.267269.

Lundskog, J. (1972) 'Heat and bone tissue. An experimental investigation of the thermal properties of bone and threshold levels for thermal injury', Scandinavian Journal of Plastic and Reconstructive Surgery, Vol. 9, pp.1-80.

Moritz, A.R. and Henriques, F.C. (1947) 'Studies of thermal injury II. The relative importance of lime and surface temperature in the causation of cutaneous burns', American Journal of Pathology, Vol. 23, pp.695-720.

MSC Marc User's Guide. Version (2007), MSC Software Corporation, Los Angeles.

Mitsuishi, M., Warisawa, S. and Sugita, N. (2004) 'Determination of the machining characteristics of a biomaterial using a machine tool designed for Total Knee Arthroplasty', CIRP Annals - Manufacturing Technology, Vol. 53, pp.107-112. 
Naohiko, S., Mamoru, M., Yoshinori, F. and Tadaaki, S. (2006) 'Relationship between anisotropic tissue and cutting stress characteristics in pig cortical bone', Journal of the Japan Society of Advanced Production Technology, Vol. 24, pp.8-13.

Ozcelik, B. and Bagci, E. (2006) 'Experimental and numerical studies on the determination of twist drill temperature in dry drilling: A new approach', Materials and Design, Vol. 279, pp.920-927.

Pallan, F.G. (1960) 'Histological changes in bone after insertion of skeletal fixation pins', Journal of Oral Surgery, Anesthesia \& Hospital Dental Services, Vol. 18, pp.400-408.

Sugita, N., Osa, T. and Mitsuishi, M. (2009) 'Analysis and estimation of cuttingtemperature distribution during end milling in relation to orthopedic surgery', Medical Engineering \& Physics, Vol. 31, pp.101-107.

Tangwongsan, C. (2003) Measurement of in vivo Endocardial and Hepatic convective heat transfer coefficient. PhD thesis. University of Wisconsin-Madison, Madison, United States.

Vashishth, D., Tanner, K.E. and Bonfield, W. (2000) 'Contribution, development and morphology of microcracking in cortical bone during crack propagation', Journal of Biomechanics, Vol. 33, pp.1169-1174. 